
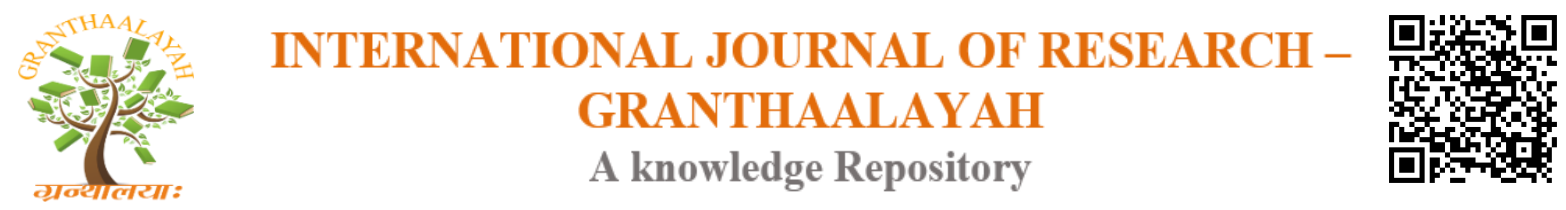

Science

\title{
EXPERIMENTAL INVESTIGATION ON THE USE OF CHICKEN FAT OIL METHYL ESTER AS ALTERNATIVE FUEL IN A DI DIESEL ENGINE IN HCCI MODE
}

\author{
B.Sachuthananthan ${ }^{* 1}$, S.Raghuramireddy ${ }^{1}$, S.Nagesh ${ }^{1}$ \\ ${ }^{1}$ Department of Mechanical Engineering, Sree Vidyanikethan Engineering College, Tirupathi, \\ India
}

\begin{abstract}
In the curiosity forever improving fuel efficiency and emissions reduction, a new and highly promising idea has found new life. HCCI (Homogeneous Charge Compression Ignition) technology has been around for a long time, but has recently received renewed attention and enthusiasm. An HCCI engine is a mix of both conventional spark-ignition and diesel compression ignition technology. The blending of these two designs offers diesel-like high efficiency without the difficulty and expensive to deal with NOx and particulate matter emissions. For the above purpose the chicken fat oil methyl ester - gasoline blend and chicken fat oil methyl ester - diesel blends are used in HCCI engine concept. The air and fuel mixture in various proportions are prepared externally by using a fuel vaporizer mounted in the intake pipe. Fuel injection is done by port fuel injector and the quantity is controlled by the electronic control unit (ECU). It can be observed from the above experimental work that the oil extracted from chicken fat can be a suitable alternative fuel to run diesel engine. Chicken fat oil methyl ester with the blend of $10 \%$ gasoline gives higher thermal efficiency than other fuel combinations with lower NOX and HC emissions.
\end{abstract}

Keywords: Chicken Fat Oil-Gasoline-Diesel Blends- HCCI Engine - Combustion and Emission Control.

Cite This Article: B.Sachuthananthan, S.Raghuramireddy, and S.Nagesh. (2018). "EXPERIMENTAL INVESTIGATION ON THE USE OF CHICKEN FAT OIL METHYL ESTER AS ALTERNATIVE FUEL IN A DI DIESEL ENGINE IN HCCI MODE." International Journal of Research - Granthaalayah, 6(2), 65-73. https://doi.org/10.5281/zenodo.1186192.

\section{Introduction}

Diesel Compression ignition (CI) and petrol spark ignition (SI) engine are the two basic technologies with established application in automotive sector. Both petrol and diesel engines use conventional fuels and have it own advantages and disadvantages. However diesel engine becomes very popular due to their adaptability for personal as well as business transportation in 
view of better and superior Aleptkin, E., Canackci et al, [2010]. However, both diesel fueled engines and petroleum fueled. However both diesel fueled engines and petroleum fueled engines are major contributors to city air pollution. Carbon monoxide(CO) and unburned hydrocarbon emissions from these engines contribute to rise in temperature of earth atmosphere. Due to severe health issues of these pollutants, rising stricter emission regulations are being adopted globally, which needs parallel reduction of particulate matter and Oxides of nitrogen emissions Amir Awaluddin, Saryono et al, [2010]. Homogeneous Charge Compression Ignition(HCCI) concept is an latest engine burning technology, which has scope for tremendous and parallel reduction in Oxides of nitrogen and particulate matter, with good efficiencies like diesel engines. In Homogeneous charge compression ignition engines combustion occur as a result of parallel auto ignition at various points throughout bigger volume Ganesh et al, [2010]. The Homogeneous charge compression ignition engines works on the concept of having a lean and premixed homogeneous charge that chemically reacts and ignites volumetrically whole of the cylinder as it is pressurized by the piston. The air and fuel mixture can be prepared either inside a system or outside of a system Ertan Alptekin et al, [2011].

Rolf Rietz et al. [2009] have experimentally investigated effect of gasoline - diesel blends in the diesel engine. For light loads $85 \%$ gasoline and $15 \%$ diesel is used and for medium and higher loads it is increased to 50-50 mix. The results were obtained, and the thermal efficiency was 53\% and there is considerable reduction in NOx and soot emission. Kambiz Tahvildari et al [2011] worked on Biodiesel extracted from waste chicken Fat sources. This paper indicates that the Chicken fat was used as a feedstock for producing the biodiesel by transesterification reaction with methanol and potassium hydroxide $(\mathrm{KOH})$. In this work chicken fat oil with $1.4 \%$ FFA, methanol and various amount of potassium hydroxide for 2 hour were studied.

The improvement in the reaction and change of triglycerides to methyl ester were investigated IR spectrum method. Xingcai Lu et al [2013] have experimentally investigated the effect of diesel and gasoline blends in single cylinder engine in HCCI combustion mode and 30\%, 40\% and $50 \%$ of gasoline is used. The effect of gasoline volume in blend, premixed ratio and the overall fuel supply rate on HCCI combustion are initially evaluated and effect of intake air boost also investigated. The results indicate that the maximum heat release rate, maximum cylinder pressure and NOx emissions of G40 and G50 compound Homogeneous charge compression ignition engines significantly increase when compared to that of G30 compound HCCI combustion. Moreover it is found that the intake air boost has large potential to reduce the NOx and soot emissions of HCCI combustion parallely. Gajendra Singh et al [2013] have experimentally verified the effect of biodiesel content on homogeneous charge compression ignition (HCCI) engine ignition.

\section{Material and Methods}

\subsection{Biodiesel Extraction from Chicken Fat}

Due to the prevailing low price of poultry meat, its production has increased to many fold in recent years furthermore, poultry products are not sidelined by any religion which increases its usage and consumption. The major producers of chicken meat in 2009 were the United States of America (15.9 million tons), China (12.1 million tons), Brazil (10.9 million tons) and the 
European Union (8.6 million tons). Brazil was in 2009 the exporting leading country of chicken meat (3.6 million tons), occupying $15 \%$ of the world market in the production of chicken meat; European Union was the third with 720 thousand tons (ABEF, 2009).

\subsubsection{Extraction of Chicken Fat Oil}

Chicken fat is extracted by heating the chicken waste in pan at temperature $120^{\circ} \mathrm{C}$ for 1 hour for the removal of moisture purpose and oil is expelled after heating and filtration.

\subsubsection{Transesterification}

Transesterification is a three-step reversible reaction that converts the initial triglycerides into a mixture of esters (biodiesel) and glycerol, in the presence of a catalyst. During the Transesterification reaction, the triglycerides are converted step by step into triglycerides, mono glycerides and glycerol, and at each step, one mol of ester is produced. The catalyst is typically sodium hydroxide (caustic soda) or potassium hydroxide (KOH). It is dissolved in the alcohol using a standard agitator or mixer. The alcohol/catalyst mix is then charged into a closed reaction vessel and the oil or fat is added. The reaction mix is kept just above the boiling point of the alcohol (around $60^{\circ} \mathrm{C}$ ) to speed up the reaction in a closed atmosphere.

\subsubsection{Transeterification Reaction}

$10 \mathrm{~g} \mathrm{KOH}$ [Base catalyst] $+350 \mathrm{ml}$ methanol $+1000 \mathrm{~g}$ of chicken fat $=1360 \mathrm{~g}$, Reaction Temperature set $=60^{\circ} \mathrm{C}$, Reaction Time $=1$ Hour $[60$ Minutes $]$, Indicator Used $=$ Phenolphthalein, Quantity taken $=1$ to 2 drops. Quantity of pure biodiesel after Transesterification from 1000gram chicken fat $=800 \mathrm{ml}$, Quantity of methanol recovery done after esterification $=50 \mathrm{ml}$. The below figure shows the chemical reaction which is taking place in the transesterification process of chicken fat oil in to pure chicken fat oil methyl ester. The transesterification reaction equation is shown below

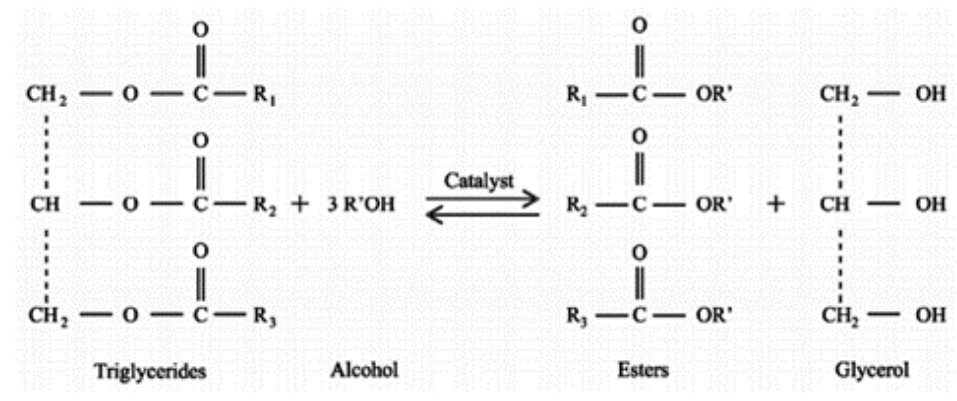

Transesterification reaction

\subsubsection{Separation of Glycerin and Biodiesel}

Once the reaction is complete, two major products exist: glycerine and biodiesel. Each has a substantial amount of the excess methanol that was used in the reaction. A successful reaction produces two liquid phases: ester and crude glycerol. The entire mixture then settles and glycerol is left on the bottom and methyl esters (Biodiesel) is left on top. Crude glycerol, the heavier 
liquid will be collected at the bottom after several hours of settling. Phase separation can be observed within 10 min and can be completed within 2 hours after stirring has stopped. Complete settling can be taken as long as 18 hours. For relatively small throughput, or batch processes, the 1 to 8 hours required for complete separation of the phases may be acceptable. The primary condition for designing a decanter for biodiesel production is the desired residence time and the product mixture flow rate determines the size of the unit. The semi-liquid glycerine has a dark brown colour and the biodiesel is honey-colored. The biodiesel yields can be calculated using the formula

$$
\text { Biodiesel Yield }=\frac{\text { mass of biodiesel }}{\text { mass of raw material }} \times 100
$$

Table 1: Comparison of Fuel Properties

\begin{tabular}{|l|l|l|l|l|}
\hline Properties & Gasoline & Diesel & CFME & Raw fat oil \\
\hline Calorific value(Mj/kg) & 44.6 & 42.8 & 35.6 & 36.2 \\
\hline Cetane number & $5-20$ & $40-55$ & 56 & 57 \\
\hline Viscosity(Cst) & $0.37-045$ & $2.6-4$ & 3.99 & 42.47 \\
\hline Density $\left(\mathrm{kg} / \mathrm{m}^{3}\right)$ & 730 & 830 & 878.2 & 921.7 \\
\hline Flash point & 260 & 110 & 90 & 130 \\
\hline Self-ignition temperature & 320 & $210-250$ & $210-300$ & $250-330$ \\
\hline Oxygen content & - & - & 11 & 11 \\
\hline
\end{tabular}

Table 2: Properties of Various Fuel Blends

\begin{tabular}{|l|l|l|}
\hline \multicolumn{2}{|l|}{ Fuel blends Calorific value $\mathbf{( M j} / \mathbf{k g})$} & Density $\left(\mathbf{k g} / \mathbf{m}^{\mathbf{3}}\right)$ \\
\hline Diesel & 42.8 & 830 \\
\hline B100 & 36.5 & 870 \\
\hline BG10 & 45.00 & 856 \\
\hline BG20 & 37.35 & 842 \\
\hline BG30 & 38.200 & 828 \\
\hline DG10 & 42.750 & 820 \\
\hline DG20 & 43.00 & 808 \\
\hline DG30 & 43.25 & 800 \\
\hline
\end{tabular}

Table 3: Engine Specifications

\begin{tabular}{|l|l|}
\hline \multicolumn{1}{|c|}{ Make } & Kirloskar \\
\hline Type & $\begin{array}{l}\text { Single cylinder, four stroke, vertical, air cooled, } \\
\text { naturally aspirated, electrical loading }\end{array}$ \\
\hline Bore & $87.5 \mathrm{~mm}$ \\
\hline Stroke & $110 \mathrm{~mm}$ \\
\hline Cylinder Volume & $662 \mathrm{cc}$ \\
\hline Compression Ratio & $17.5: 1$ \\
\hline Combustion Chamber & Hemispherical Bowl in piston \\
\hline Rated Speed & $1500 \mathrm{rpm}$ \\
\hline
\end{tabular}




\begin{tabular}{|l|l|}
\hline Power & $4.4 \mathrm{~kW}$ \\
\hline Nozzle Opening Pressure & $200 \mathrm{bar}$ \\
\hline Number of Orifices & 3 \\
\hline Fuel Injection Timing (static) & $23^{\mathrm{O}} \mathrm{bTDC}$ \\
\hline Specificfuel consumption (SFC) & $251 \mathrm{kWh}$ \\
\hline
\end{tabular}

Table 1 represent the details of various fuel properties, the properties of various fuel blends and the engine specification are mentioned in Table 2, and Table 3 respectively.

\section{Experimental Procedure}

The Experimental work involves observing and taking safety precautions, observations and noting down the engine performance, emissions and combustion parameters using appropriate Instruments. It includes intake air measurement, fuel measurement, power measurement, cylinder pressure measurement and emission measurements. The schematic diagram and photographic view of the experimental set up is shown in Figure 1(a) and Figure 1(b). Two separate fuelmeasuring systems were provided to measure both conventional fuel injector and a low-pressure injector. The fuel supplied to the low-pressure injector was preset. If the present quantity was not enough to maintain the rated speed then the fuel was adjusted to maintain the speed and the corresponding fuel consumption was calculated from Figure 1(a). The electrical dynamometer was used for measuring power output of the engine.

The electrical power created by the dynamometer is usually released as heat through set of electrical resistances. The load and speed of the engine can be enhanced or decreased on the dynamometer and thereby on the engine, by switching on or off the load resistances and by varying the field strength. Exhaust emission from the engine was measured with the help of AVL DI Gas 444 analyzer and smoke intensity was measured with the help of Bosch AVL 437 smoke meter. Two separate sampling probes were used to receive sample exhaust gases from the engine for measuring emission and smoke intensity, respectively. A $50 \mathrm{~mm}$ diameter filter paper was used to collect smoke samples from the engine. A K-type thermocouple and a temperature indicator were used to measure the exhaust gas temperature. A Kistler (601A) water cooled pressure transducer was used to measure cylinder. A Kistler crank angle encoder on the crankshaft (7200 points per cycle) was used to measure pressure data acquisition. For each measured point, the pressure data of 100 cycles were recorded. The analysis software AVL indicom to determine the Heat release rate, cumulative heat release rate, etc. At the beginning engine was started at no load for engine to warm up. Once ECU gives the signal to inject the fuel into the vaporizer which was maintained at a temperature of $260 \mathrm{oC}$ provides the fuel vapour into the intake manifold. In the manifold the fuel vapour mixed with air to form a homogeneous $\backslash$ mixture. This homogeneous mixture was inducted inside the cylinder during the intake stroke. When the engine attained the rated speed through fuel vapour-air mixture induction, the engine governor cuts the fuel supply to the conventional fuel injector (200 bar pressure) thereon the engine operated completely in homogeneous mixture of diesel vapour-air mixture. Thus ensures that engine switched to diesel HCCI operation. The same procedure is followed for different fuel blends for HCCI and C.I operation. 


\subsection{Estimation of Uncertainty}

Ambiguities and uncertainties are to be estimated while conducting an experimental analysis. These inaccuracies may arise due to environmental factors, errors in calibration of instruments, human errors while observation and reading. The uncertainty values of measured parameters were estimated from the range and accuracy of instruments and are shown in Table 4. In order to get more accurate uncertainty limits for computed parameters the principle of root sum square method was used and it is given by equation -1 .

$\mathrm{R}=\sum \mathrm{Xi} 2$

where $\mathrm{R}$ is the total percentage of uncertainty and $\mathrm{Xi}$ is the individual uncertainty of computed parameters. the total percentage uncertainty of computed parameters were calculated and given below

$$
\begin{gathered}
\mathrm{R} 1=\mathrm{X} 12+\mathrm{X} 22+\mathrm{X} 32+\mathrm{X} 42+\mathrm{X} 52 \\
\mathrm{R}=(1) 2+(.4) 2+(1) 2+(.1) 2+(.2) 2 \\
\mathrm{R}= \pm 1.48 \%
\end{gathered}
$$

\section{Results and Discussion}

\subsection{General}

The results obtained from the present work in terms of performance, combustion and emission characteristics of the engine observed detailed. All the results are presented with a comparison between the characteristics of conventional diesel, biodiesel, and also with different fuels blends of gasoline with diesel and biodiesel.

\subsection{Performance Characteristics}

\subsubsection{Heat Release Rate}

Figure 2. shows the heat release rate patterns with respect to loads and various fuel blends. From the Figure 2, it is observed the heat release rate increased on increasing the concentration of gasoline in diesel and in the biodiesel. The heat release rate of diesel was found to be lower than the other fuels. The start of low temperature reactions is delayed and peaks of them are reduced. At high load conditions, the peak of cool flame reduces due to a reduction in the diesel flow rate.

\subsubsection{Cylinder Pressure}

The combustion characteristics were analyzed based on the measured in-cylinder pressure. Figure.3 shows the variations of cylinder pressures with different loads at different fuel combinations. From the figures, it can be seen that the occurrence of peak pressure advances with respect to the top dead centre with an increase in load. Also, the occurrence of peak pressure retards with an increase in gasoline blends. This leads to an increased rate of pressure rise and engine noise, whereas the cylinder pressure reduces for diesel and the occurrence of 
peak pressure is maximum in biodiesel gasoline blends. The ignition delay has been increased in increasing the gasoline concentration in both diesel and biodiesel and the engine knock increases at higher load with these blends. The B100 also has variable increase in peak pressure compared to diesel. In general, peak pressure varies from about 40 to 75 bars for the entire load range considered.

\subsubsection{Brake Thermal Efficiency}

The effect of brake thermal efficiency over various loads is shown in Figure 4. There is a steady rise in brake thermal efficiency as the load increases in all the cases. As the brake thermal efficiency is a function of chemical energy and the brake power developed from it, BG10 fuelled operation resulted in higher brake thermal efficiency compared to diesel and other fuel blends.

\subsection{Emission Characteristics}

\subsubsection{HC Emission}

The variation of unburned hydrocarbons over various loads is shown in Figure 5. Improper combustion of fuel, improper fuel injection timing and low combustion chamber temperature are the few reason for the formation of $\mathrm{HC}$ emissions. It is found from the graphs that the Hydro carbon emissions increase for all loads and for all fuels. At 75\% load $\mathrm{HC}$ emissions decreases for all fuel blends except diesel.

\subsubsection{Oxides of Nitrogen}

Figure 6 shows that High temperature and availability of excess oxygen inside the engine cylinder contributes to the formation of NOX emission. The NOx formed in the engine cylinder is basically the combination of $\mathrm{NO}$ and NO2. It can be seen from the graphs that the oxides of nitrogen increase with increase in load for all the fuel blends. For B100 NOx emission is found to be high compared to other fuels and diesel has low NOx emission.

\subsubsection{Smoke}

The smoke density is decreased with increase in gasoline \% in both diesel and biodiesel. The diesel has maximum smoke density at full load. At part load smoke decreased for DG20 which is shown in figure.7.

\subsubsection{Carbon Monoxide}

Insufficient quantity of oxygen and less cycle time are the two-main reason for the formation of $\mathrm{CO}$ emission. In this experimental work the $\mathrm{CO}$ emission is found to be higher for diesel and $30 \%$ biodiesel gasoline blends only at higher loads. This may be due to the reason that as the oxygen content in the fuel increases the $\mathrm{CO}$ formation decreases due to the oxidation of $\mathrm{CO}$ to $\mathrm{CO} 2$ it is represented in Figure. 8 


\section{Conclusion}

It can be concluded from the above experimental investigation that the oil extracted from chicken fat can a suitable fuel to run diesel engine. Chicken fat oil methyl ester with the blend of $10 \%$ gasoline gives thermal efficiency than other fuel combinations. With respect to the combustion characteristics like in cylinder pressure the occurrence of peak pressure retards with an increase in gasoline blends whereas the cylinder pressure reduces for diesel and the occurrence of peak pressure is maximum in biodiesel gasoline blends. It can be seen from the graphs that Hydro carbon emissions increase for all loads and for all fuels. At $75 \%$ load $\mathrm{HC}$ emission decreases for all fuel blends except diesel. The NOx emission is found to be high for pure chicken fat oil methyl ester and it is low for pure diesel which is attributed to the oxygen content of the fuels. The $\mathrm{CO}$ and smoke emission is also found to be high for diesel and it is found to be low for blends of chicken fat oil methyl ester and gasoline blends. The quality of combustion and the other combustion characteristics of the biofuel is found to be the reason for lower emissions. It can be concluded that when compared to conventional fuel chicken fat oil methyl ester combined with $10 \%$ gasoline gives higher thermal efficiency and lower engine out emissions when compared to other fuels. Hence to operate the diesel engine in HCCI mode chicken fat oil methyl ester with gasoline blend is found to be a suitable fuel.

\section{Acknowledgement}

I would first like to thank our chairman Dr M. MOHAN BABU for his continuous support to the progress of the work. The doors of our chairman office were always open whenever I ran into a trouble spot or had a question about my research or writing. He consistently allowed this paper to be my own work, but steered me in the right the direction whenever he thought I needed it.

I would also like to thank our Head of the Department Dr K C VARAPRASAD who constantly encouraged us in consistently doing this work. I would also like to acknowledge faculty members of our mechanical engineering department to helped us in accomplishing this research work.

Finally, I must express my very profound gratitude to my parents and to my partner, spouse and my children's who spared their time without me and for providing me with unfailing support and continuous encouragement throughout my research work. This accomplishment would not have been possible without them

\section{References}

[1] Aleptkin, E., Canackci, M. "Optimization of pre-treatment reaction for methyl ester production from chicken fat". Fuel. 89, (2010). 4035-4039.

[2] Amir Awaluddin, Saryono, Adhy Prayitno and Tearful Amri, "Transesterification of Waste Chicken Fats for Synthesizing Biodiesel by $\mathrm{CaO}$ as Heterogeneous Base Catalyst", International Conference on Energy and Sustainable Development: Issues and Strategies, (2010), 1 -5.

[3] D. Ganesh, G. Nagarajan, "Homogeneous charge compression ignition (HCCI) combustion of diesel fuel with external mixture formation".Energy 35 (2010) 148-157.

[4] Ertan Alptekin, Mustafa Canakci., "Optimization of transesterification for methyl ester production from chicken fat”, science direct, Fuel 90 (2011) 2630-2638. 
[5] Heike Puschmann, Ralf Buchwald, Marcel Pannwitz, Ansgar Sommer, "Homogeneous diesel combustion with external mixture formation by a cool Flame Vaporizer". SAE Paper 2006-01$3323,14-24$.

[6] Hua Zhao. "HCCI and CI engines for the automotive industry". Woodhead Publishing in Mechanical Engineering.

[7] Kambiz Tahvildari, Narges Davari, Mohammadreza Allahgholi Ghasri, Masoomeh Behrourzinavid., "Biodiesel Production from Waste Chicken Fat based Sources". World Academy of Science, Engineering and Technology. 12-18.

[8] Metin Guru, Atilla Koca, O zer Can, Can Cınar, Fatih S.Ahin. "Biodiesel production from waste chicken fat-based sources and evaluation with $\mathrm{Mg}$ based additive in a diesel engine", Science direct, Renewable Energy 35 (2010) 637-643.

[9] Rudolf H. Stanglmaier and Charles E. Roberts., "Homogeneous Charge Compression Ignition (HCCI): Benefits, Compromises, and Future Engine Applications"., SAE technical paper series 1999-01-3682,1543-1554.

[10] Ryan TW III, Callahan TJ. "Homogeneous charge compression ignition of diesel fuel", SAE Technical Paper 961160; 1996.675-681

[11] Su Han Park, In Mo Youn, Yunsung Lim, Chang Sik Lee., "Influence of the mixture of gasoline and diesel fuels on droplet atomization, combustion, and exhaust emission characteristics in a compression ignition engine", Science direct, Fuel Processing Technology 106 (2013) 392-401.

[12] Xingcai Lu, Yong Qian, Zheng Yang, Dong Han, Jibin Ji, Xiaoxin Zhou, Zhen Huang Madeline Yozwiak., "Experimental study on compound HCCI (homogenous charge compression ignition) combustion fuelled with gasoline and diesel blends", Science direct, Energy 64 (2014) 707-718.

[13] Najt, P. M. and Foster, D. E., "Compression Ignited Homogeneous Charge Combustion," SAE paper 830264,1983.154-165

[14] Noguchi, M., Tanaka, Y., Tanaka, T., and Takeuchi, Y., "A Study on Gasoline Engine Combustion by Observation of Intermediate Reactive Products During Combustion," SAE paper 790840, 19,897-895.

[15] Iida, N., "Alternative Fuels and Homogeneous Charge Compression Ignition Combustion Technology," SAE paper 972071, 1997.456-465.

*Corresponding author.

E-mail address: bsachu7@yahoo.co.in 